\title{
Studying the Effects of Waterhemp Competition on Yield and Phytochemical Content of High-cannabidiol Hemp in Plasticulture
}

\author{
Avery Shikanai ${ }^{1}$ and Karla L. Gage ${ }^{1,2}$
}

AdDitional Index words. Amaranthus tuberculatus, Cannabis sativa, cannabidiol, CBD, tetrahydrocannabinol, THC, terpene

SUMmaRY. The impacts of weed interference on hemp (Cannabis sativa) yield are largely unstudied despite causing serious economic losses in most cropping systems. For high-cannabidiol (CBD) hemp, understanding the role of weed competition on CBD and tetrahydrocannabinol (THC) content may help promote profitability and regulatory compliance. Therefore, we tested the effects of varying waterhemp [Amaranthus tuberculatus (zero, one, three, and five waterhemp plants per planting hole)] and hemp (zero or one hemp plants per planting hole) planting densities on total hemp yield, chemical composition, and aboveground waterhemp biomass in plasticulture. There was no significant total biomass or stripped floral biomass yield loss resulting from waterhemp competition, although unexpectedly high variation in hemp phenotypes likely limited the ability to detect subtle differences between treatments. Furthermore, there was no significant effect of competition treatment on total CBD, total THC, or measured terpene composition. However, waterhemp biomass was reduced significantly by competition from hemp in comparison with hemp-free treatments. Suppression of waterhemp by hemp and lack of significant yield loss suggest that hemp can be highly competitive and grown successfully without herbicides in certain circumstances.

$\mathrm{H}$ emp (Cannabis sativa) is a new crop for producers in the United States, and information on weed competition in relation to crop quality and yield is limited. After decades of prohibition, the 2018 Farm Bill allowed for cultivation of hemp plants containing less than $0.3 \%$ THC on a dry weight basis (U.S. House of Representatives, 2018).

Received for publication 11 June 2021. Accepted for publication 7 Dec. 2021.

Published online 1 February 2022.

${ }^{1}$ School of Biological Sciences, Southern Illinois University Carbondale, 1125 Lincoln Drive, Carbondale, IL 62901

${ }^{2}$ School of Agricultural Sciences/Cannabis Science Center, Southern Illinois University Carbondale, 1205 Lincoln Drive, Carbondale, IL 62901

This paper is based on a portion of a thesis submitted by Avery Shikanai in fulfilling the requirements of an MS degree.

We thank committee members David Gibson and Aldwin Anterola for their constructive review. We thank Erik Larsen, John Miller, Austin J. Barron, and Ryder Hales for their invaluable field assistance, and Mary Kinsel for help with chemical analysis. We thank the journal editors and anonymous reviewers for their helpful comments.

K.L.G. is the corresponding author. E-mail: kgage@ siu.edu.

This is an open access article distributed under the CC BY-NC-ND license (https://creativecommons. org/licenses/by-nc-nd/4.0/).

https://doi.org/10.21273/HORTTECH04902-21
Crops accumulating more than $0.3 \%$ THC are legally termed marijuana and must be destroyed at a substantial loss to the grower. Although hemp can be grown for fiber and seed, most hemp in the United States is being produced for pistillate flowers, which are covered in glandular trichomes that accumulate terpenes and cannabinoids, which are secondary metabolites with therapeutic and sensory value (Fike et al., 2020).

The dominant cannabinoid found in hemp is cannabidiolic acid (CBDa), whereas marijuana predominantly accumulates tetrahydrocannabinolic acid (THCa). CBDa and THCa have low affinity for human cannabinoid receptors.
However, CBDa and THCa may be decarboxylated by heating, forming biologically active CBD or THC, respectively (Flores-Sanchez and Verpoorte, 2008). Hemp-derived CBD is increasingly valued for its therapeutic potential, as it shows anticonvulsant and anti-inflammatory properties (Devinsky et al., 2014; Zou and Kumar, 2018).

In addition to cannabinoids, hemp glandular trichomes are rich in terpenes, chemicals with ecological, sensory, and therapeutic implications. Dozens of terpenes have been identified in hemp (Sommano et al., 2020), endowing it with its distinct aroma. The aroma of hemp is an important trait associated with consumer perception of quality, price, and potency (Gilbert and DiVerdi, 2018). In addition, terpenes have agroecological implications and ostensibly serve as insect deterrents (McPartland and Sheikh, 2018). In addition to ecological functions, terpenes show promise in food and medical applications. Many terpenes are antimicrobial and can be used as natural food preservatives (Guimarães et al., 2019; Khameneh et al., 2019). Furthermore, $\beta$-caryophyllene, a sesquiterpene and major component of hemp essential oil, binds to the cannabinoid receptor CB2 and shows promise as an anti-inflammatory drug (Gertsch et al., 2008).

Although CBD content is valuable to producers, excessive THC in a hemp crop has potentially major economic and legal repercussions. Unfortunately, hemp intended for CBD production often accumulates violative levels of THC and must be destroyed (Alberti, 2021). Some instances of elevated THC in hemp are likely a result of the segregation of genes controlling the production of CBDa and THCa (Toth et al., 2020). However, plants without the

\begin{tabular}{llll}
\hline $\begin{array}{l}\text { Units } \\
\begin{array}{l}\text { To convert U.S. to SI, } \\
\text { multiply by }\end{array}\end{array}$ & U.S. unit & SI unit & $\begin{array}{l}\text { To convert SI to U.S., } \\
\text { multiply by }\end{array}$ \\
\hline 29,574 & $\mathrm{fl} \mathrm{oz}$ & $\mu \mathrm{L}$ & $3.3814 \times 10^{-5}$ \\
29.5735 & $\mathrm{fl} \mathrm{oz}$ & $\mathrm{mL}$ & 0.0338 \\
0.3048 & $\mathrm{ft}$ & $\mathrm{m}$ & 3.2808 \\
2.54 & inch $(\mathrm{es})$ & $\mathrm{cm}$ & 0.3937 \\
25.4 & inch $(\mathrm{es})$ & $\mathrm{mm}$ & 0.0394 \\
1.1209 & $\mathrm{lb} / \mathrm{acre}$ & $\mathrm{kg} \cdot \mathrm{h}^{-1}$ & 0.8922 \\
1 & $\mathrm{micron}(\mathrm{s})$ & $\mu \mathrm{m}$ & 1 \\
0.0254 & $\mathrm{mil}(\mathrm{s})$ & $\mathrm{mm}$ & 39.3701 \\
28.3495 & $\mathrm{oz}$ & $\mathrm{g}$ & 0.0353 \\
0.001 & $\mathrm{ppm}$ & $\mathrm{g} \cdot \mathrm{L}^{-1}$ & 1000 \\
0.001 & $\mathrm{ppm}$ & $\mathrm{mg} \cdot \mathrm{mL}^{-1}$ & 1000 \\
1 & $\mathrm{ppm}$ & $\mu \mathrm{g} \cdot \mathrm{g}^{-1}$ & 1 \\
$\left({ }^{\circ} \mathrm{F}-32\right) \div 1.8$ & ${ }^{\circ}$ & ${ }^{\circ} \mathrm{C}$ & $\left({ }^{\circ} \mathrm{C} \times 1.8\right)+32$
\end{tabular}

Horllechnology $\cdot$ April $202232(2)$ 
Table 1. Planting densities of hemp and waterhemp per planting hole. Within 1 year, each treatment was replicated eight times in a randomized complete block design.

\begin{tabular}{lcc}
\hline Treatment & $\begin{array}{c}\text { Waterhemp plants } \\
\text { (no./ }\end{array}$ & $\begin{array}{c}\text { Hemp planting hole) } \\
\text { (no./planting hole) }\end{array}$ \\
\hline Control & 0 & 1 \\
Low competition & 1 & 1 \\
Medium competition & 3 & 1 \\
High competition & 5 & 1 \\
No hemp, low competition & 1 & 0 \\
No hemp, medium competition & 3 & 0 \\
No hemp, high competition & 5 & 0 \\
\hline
\end{tabular}

marijuana-type marker still often produce violative levels of THC. Therefore, a greater understanding of environmental and cultural factors influencing THC content is needed.

Anecdotally, producers have suggested that stressful conditions caused by weed competition are responsible for increased THC in hemp crops. Exploitative competition for resources can cause decreased availability of nutrients and water, conditions that alter secondary metabolite accumulation in multiple system (Yang et al., 2018 ). Changes in secondary metabolite accumulation in many species involve factors beyond simple resource limitation. Instead, many plants have the capacity to sense their neighbors and adjust their growth and metabolism appropriately. For example, exposure of the shade-intolerant longflower tobacco (Nicotiana longiflora) to farred light suppresses accumulation of herbivory defense compounds (Izaguirre et al., 2006). Likewise, when grown in the presence of barnyardgrass (Echinochloa crus-gali) exudates, rice (Oryza sativa) produces the allelochemical momilactone B (Kato-Noguchi, 2011). However, the impact of environmental factors on hemp secondary metabolite content are not well understood. Resource limitation caused by weeds could affect THC content, as moderate drought (Caplan et al., 2019) and reduced nutrient availability (Caplan et al., 2017) can increase THC content of medical marijuana. However, little is known about the effects of weed competition on hemp grown for cannabidiol.

Hemp grown for cannabinoids and terpenes is often grown in highintensity plasticulture systems (Fike et al., 2020). Opaque plastic mulches can alter the plant microenvironment to improve crop growth and suppress weeds. However, weeds can still emerge through holes in plastic mulch and compete with the crop. U.S. producers typically rely on herbicides to control weeds, but there are currently no herbicides labeled for use in hemp in the United States (Flessner et al., 2020). Lack of control options makes understanding the effects of weeds on hemp yield and chemical composition a research priority (Ellison, 2021). Waterhemp (Amaranthus tuberculatus) is a common and troublesome weed for producers of high-value horticultural crops (Van Wychen, 2019). Documented resistance to seven herbicide sites of action (Heap, 2021) has made waterhemp especially abundant and problematic for growers in Illinois. Furthermore, the competitive ability of waterhemp (Butts et al., 2018) makes it a serious threat to most crops if left uncontrolled. Therefore, the objectives of our study are 1) to study the effects of competition from waterhemp on total hemp biomass and floral biomass yield in plasticulture, and 2) to determine whether waterhemp competition can alter the THC, CBD, and terpene composition and content of hemp.

\section{Materials and methods}

The experiment took place at the Southern Illinois University Horticulture Research Center in Carbondale, IL (lat. $37.713351^{\circ} \mathrm{N}$, long. $89.269780^{\circ} \mathrm{W}$ ) on a Hosmer silt loam soil. We studied a seed-derived, pistillate hemp accession (21 Mother PH4) developed for CBD production. We tested the effects of varying waterhemp and hemp planting densities on hemp yield, height, chemical composition, and aboveground waterhemp biomass

Table 2. Total biomass, stripped floral biomass, height, and total cannabidiol (CBD) content of hemp in response to zero, one, three, or five waterhemp competitors per planting hole in 2019 or 2020 . Within a year, there were no significant differences in total hemp biomass, stripped floral biomass, height, or total CBD as a result of waterhemp competition treatment.

\begin{tabular}{|c|c|c|c|c|c|c|c|c|c|c|c|c|c|}
\hline \multirow[b]{2}{*}{ Yr } & \multirow{2}{*}{$\begin{array}{c}\text { Waterhemp } \\
\text { (no./planting } \\
\text { hole) }\end{array}$} & \multicolumn{3}{|c|}{$\begin{array}{c}\text { Total hemp } \\
\text { biomass }(\mathrm{g} / \text { plant })^{\mathrm{z}}\end{array}$} & \multicolumn{3}{|c|}{$\begin{array}{l}\text { Stripped hemp floral } \\
\text { biomass (g/plant) }\end{array}$} & \multicolumn{3}{|c|}{ Final hemp ht $(\mathrm{cm})^{\mathrm{z}}$} & \multicolumn{3}{|c|}{ Total CBD $(\%)^{y}$} \\
\hline & & $\begin{array}{c}\text { Lower } \\
95 \% \mathrm{CL}\end{array}$ & Mean & $\begin{array}{c}\text { Upper } \\
95 \% \mathrm{CL}\end{array}$ & $\begin{array}{c}\text { Lower } \\
95 \% \mathrm{CL}\end{array}$ & Mean & $\begin{array}{l}\text { Upper } \\
95 \% \mathrm{CL}\end{array}$ & $\begin{array}{c}\text { Lower } \\
95 \% \mathrm{CL}\end{array}$ & Mean & $\begin{array}{l}\text { Upper } \\
95 \% \mathrm{CL}\end{array}$ & $\begin{array}{c}\text { Lower } \\
95 \% \mathrm{CL}\end{array}$ & Mean & $\begin{array}{l}\text { Upper } \\
95 \% \mathrm{CL}\end{array}$ \\
\hline \multirow[t]{3}{*}{2019} & 0 & 923 & 1,168 & 1,413 & 601 & 755 & 908 & 129 & 141 & 153 & 7.82 & 9.42 & 11.03 \\
\hline & 1 & 907 & 1,152 & 1,397 & 581 & 734 & 887 & 122 & 134 & 146 & 6.36 & 8.1 & 9.84 \\
\hline & 3 & 736 & 980 & 1,225 & 508 & 662 & 815 & 111 & 123 & 135 & 9 & 10.61 & 12.21 \\
\hline \multirow{3}{*}{2020} & 1 & 456 & 660 & 864 & 297 & 406 & 515 & 127 & 141 & 156 & 9.91 & 12.1 & 14.2 \\
\hline & 3 & 526 & 731 & 935 & 341 & 450 & 559 & 144 & 158 & 172 & 9 & 11 & 12.9 \\
\hline & 5 & 357 & 561 & 765 & 261 & 370 & 480 & 126 & 140 & 154 & 9.89 & 11.9 & 13.9 \\
\hline
\end{tabular}

\footnotetext{
${ }^{\mathrm{z}} \mathrm{l} \mathrm{g}=0.0353 \mathrm{oz}, \mathrm{l} \mathrm{cm}=0.3937$ inch.

${ }^{\mathrm{y}}$ Total $\mathrm{CBD}=\mathrm{CBD}+(0.877 \times \mathrm{CBDa})$, where $\mathrm{CBDa}$ is cannabidiolic acid.

$\mathrm{CL}=$ confidence limit.
} 
in a plasticulture system. There were seven treatment combinations tested (Table 1 ) in a randomized complete block design with eight replications. The experimental unit consisted of a hole in the mulch planted with one of the treatments listed in Table 1 . We performed the experiment during the 2019 and 2020 growing seasons.

In both years, 6-week-old hemp transplants grown from seed were planted into raised beds $(15 \mathrm{~cm}$ high and $30 \mathrm{~cm}$ wide) on 5 -ft centers covered with 1.0-mil low-density polyethylene mulch. Within rows, the between-plant spacing was $5 \mathrm{ft}$. In 2019, hemp transplants were 15 to $20 \mathrm{~cm}$ tall and bore 9 to 10 pairs of true leaves; the plants were transplanted into the field on 18 June 2019. In 2020, hemp transplants 36 to $50 \mathrm{~cm}$ tall bearing 10 to 15 pairs of true leaves were transplanted on 15 June. In both years, the experiment was bordered by additional rows of hemp plants to minimize edge effects. Drip tape running directly beneath the polyethylene mulch was used to supply nitrogen at $108 \mathrm{lb} /$ acre as calcium nitrate during vegetative growth and to supply water as needed. In 2019 , holes $\approx 10 \mathrm{~cm}$ in diameter were made to accept hemp transplants. In 2020 , to facilitate waterhemp establishment more effectively, hemp was transplanted into square holes in the mulch measuring $20 \times 20 \mathrm{~cm}$. Although $20 \times 20$-cm holes are slightly larger than what is typically used in plasticulture production, larger planting holes have been used when studying weed competition in plasticulture systems (Bertucci et al., 2019). In both years, $\approx 50$ waterhemp seeds were sown into each planting hole immediately after transplanting, except for the control treatments. In both years, waterhemp began emerging $\approx 5$ $\mathrm{d}$ after sowing. Two weeks after sowing, waterhemp was thinned to the assigned treatment densities, retaining the largest seedlings (Table 1). Experimental units were scouted at least once per week to rogue nontarget species and late-emerging waterhemp.

In 2019, between-row weeds were managed with a combination of cultivation and mowing. In 2020, weeds were managed with a single application of $2.4 \mathrm{~kg} \cdot \mathrm{ha}^{-1}$ glyphosate (Monsanto, St. Louis, MO) mixed with $1.3 \mathrm{~kg} \cdot \mathrm{ha}^{-1}$ $S$-metolachlor (Syngenta, Greensboro,
NC). In 2019, insect pests were managed by hand-picking. In 2020, insect pests were managed by a combination of hand-picking and applications of 2.4 $\mathrm{g} \cdot \mathrm{L}^{-1}$ Bacillus thuringiensis (Valent Biosciences, Libertyville, IL) every 7 to $10 \mathrm{~d}$ during flowering.

In 2019, we suspect that a small amount of glyphosate drifted onto the experiment from a neighboring field. Injury to hemp plants presented itself as slight chlorosis in the upper leaves and dissipated within 2 weeks. The experiment was blocked spatially in increasing distance from the adjacent field, and no visual injury was observed on any waterhemp plants. In 2020 , the experiment was planted in a different field at the Horticulture Research Center $\approx 800 \mathrm{ft}$ from the 2019 location. No herbicide injury was observed in 2020.

Hemp height was measured every 7 to $14 \mathrm{~d}$ after transplanting. In 2019, the experiment was harvested on 8 Oct., and in 2020 the experiment was harvested on 7 Oct. In both years, hemp was harvested after all plants stopped growing in height and glandular trichomes started to become cloudy. Hemp was harvested by cutting plants at soil level, and was dried in a forced-air oven at $60^{\circ} \mathrm{C}$, except for samples used for chemical analysis. After drying to a constant weight, total dry weight and separated hemp floral biomass were measured. Waterhemp was harvested by cutting plants at the soil level and was dried to constant weight in a forced-air oven at $60{ }^{\circ} \mathrm{C}$. Waterhemp biomass accumulation was recorded as zero in cases where a plant died and could not be recovered.

Chemical analysis. In both years, several plants were infected with an unknown stem blight just before harvest and were excluded from chemical analysis. The uppermost 20 $\mathrm{cm}$ of each hemp plant was removed at harvest, dried overnight at $40^{\circ} \mathrm{C}$, and homogenized with a commercial
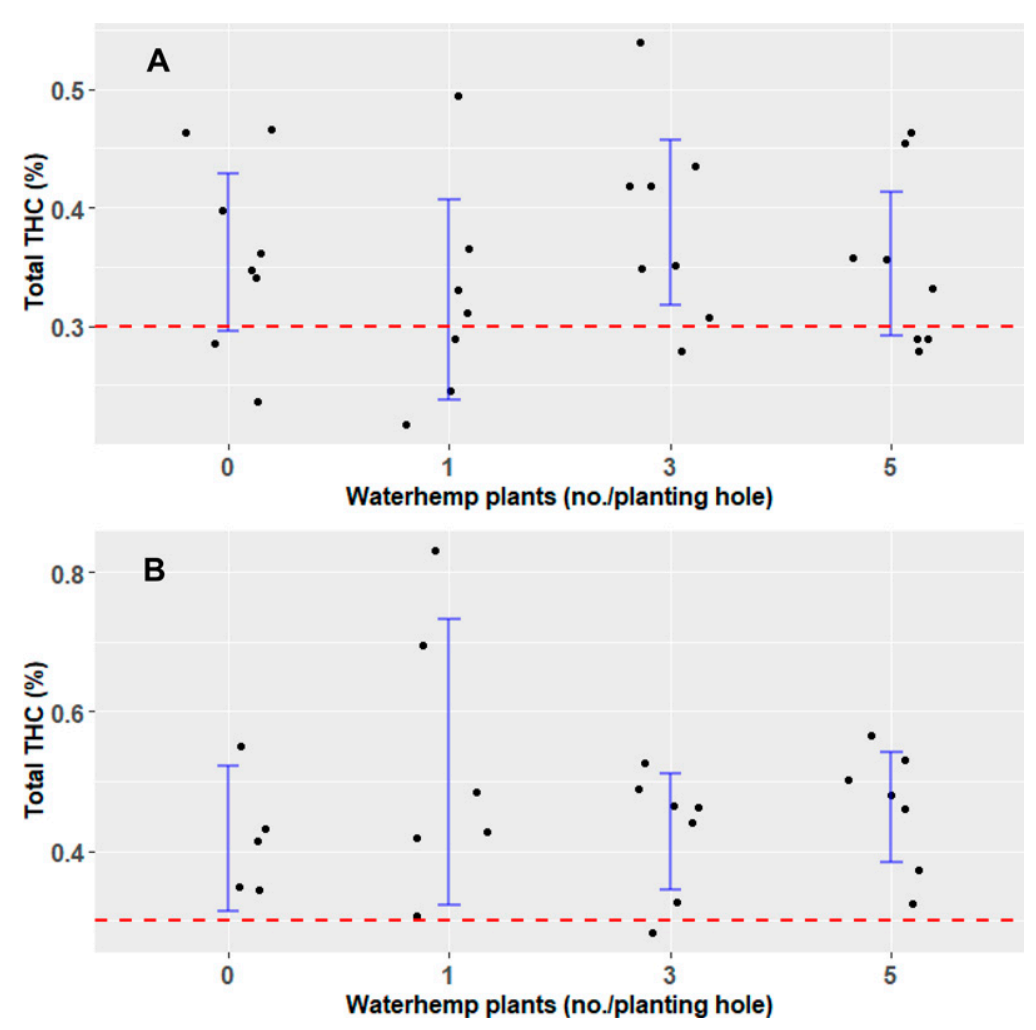

Fig. 1. Total tetrahydrocannabinol (THC) of hemp in response to competition from zero, one, three, or five waterhemp plants per planting hole in (A) 2019 and (B) 2020. Light-blue bars represent $95 \%$ confidence intervals. Black points represent individual observations. The dashed red line represents the $0.3 \%$ regulatory threshold. Total THC is determined by the formula: THC $+(0.877 \times$ THCa), where THCa is tetrahydrocannabidiolic acid. There was no significant effect of waterhemp density on total THC content in 2019 or in 2020 . Four outliers accumulating more than $4 \%$ total THC were excluded from analysis, although inclusion yields qualitatively similar results (Supplemental Fig. 1). 
coffee grinder. Samples consisted of floral bracts, leaves, and stems, and were stored in the dark in air-tight containers at room temperature until analysis in accordance with recommendations from the United Nations Office on Drugs and Crime (2009). Chemical analysis was performed at the Southern Illinois University Cannabis Science Center's analytical facilities. Homogenized hemp was sifted using a $1.0-\mathrm{mm}$ sieve; $0.2 \mathrm{~g}$ of dried tissue was sonicated in $10 \mathrm{~mL}$ highperformance liquid chromatography (HPLC)-grade methanol for $30 \mathrm{~min}$. The supernatant was passed through a $0.45-\mu \mathrm{m}$ syringe filter and $\mathrm{l} \mathrm{mL}$ was transferred to an autosampler vial for terpene analysis by gas chromatography with a flame ionization detector. For cannabinoid analysis, filtered supernatant was diluted further with HPLC-grade methanol, forming a 1:50 dilution.

Terpenes were separated using a gas chromatography-flame ionization detector (6890; Agilent Technologies, Santa Clara, CA) equipped with a fused silica column (RXi-35Sil MS; Restek, Bellefonte, PA). The injection volume was $5 \mu \mathrm{L}$. The initial oven temperature was held at $50^{\circ} \mathrm{C}$ for $\mathrm{l}$ min and then ramped at $10^{\circ} \mathrm{C} \cdot \mathrm{min}^{-1}$ to $280^{\circ} \mathrm{C}$, where it was held for $6 \mathrm{~min}$. The inlet was $250^{\circ} \mathrm{C}$ and operated in a 10:1 split mode; the column flowrate was 2.0 $\mathrm{mL} \cdot \mathrm{min}^{-1}$. Samples were analyzed for 19 terpenes: $\alpha$-pinene, (-)- $\alpha$-bisabolol, (-)- $\beta$-pinene, camphene, d-limonene, geraniol, guaiol, isopulegol, linalool, nerolidol, ocimene, $\mathrm{p}$-cymene, terpinolene, $\alpha$-humulene, $\alpha$-terpinene, $\beta$-caryophyllene, $\beta$-myrcene, $\gamma$-terpinene, and $\delta$ - 3 -carene using calibration standards (Terpene mix 1, Restek).

Cannabinoids were separated using HPLC (1200, Agilent Technologies) with an ultraviolet-vis photodiode array detection equipped with a C18 $(4.6 \times 50-\mathrm{mm}, 2.6-\mu \mathrm{m}, 100-\AA)$ column (Kintex; Phenomenex, Torrance, CA), detecting at $230 \mathrm{~nm}$. Mobile phase A was 18 Mohm water (MilliporeSigma, Burlington, MA) with $0.1 \%$ formic acid; mobile phase $\mathrm{B}$ was HPLC-grade methanol with $0.1 \%$ formic acid. The gradient elution program began at $60 \% \mathrm{~B}$ and reached $90 \% \mathrm{~B}$ at $12 \mathrm{~min}$, where it was held for $2 \mathrm{~min}$. The column oven was set to $45^{\circ} \mathrm{C}$ and the injection volume was $10 \mu \mathrm{L}$. The column flowrate was 1.0
$\mathrm{mL} \cdot \mathrm{min}^{-1}$. THCa, THC, CBDa, and CBD were quantitated using calibration standards prepared from certified reference materials purchased in 1 $\mathrm{mg} \cdot \mathrm{mL}^{-1}$ concentrations (Cayman Chemical, Ann Arbor, MI). Total THC and total CBD were calculated by summing concentrations of the decarboxylated cannabinoid and the concentrations of $\mathrm{THCa}$ or $\mathrm{CBDa}$ multiplied by 0.877 .

Hemp CHEMical Yield DATA ANALYSIS. A mixed-model analysis of variance (ANOVA) was conducted to test for the effects of planted waterhemp density treatment on total THC, total CBD, and total terpene concentration. Waterhemp planting density was modeled as a fixed effect, and block was modeled as a random effect. Analysis was conducted in R ( R Foundation for Statistical Computing, Vienna, Austria) using the lme4 package (Bates et al., 2015). Four hemp plants with more than $4 \%$ total THC were considered outliers and were dropped from the analysis of chemical content. However, inclusion of outliers yielded qualitatively similar results. Total terpene content was determined as the sum of all terpenes measured and quantified by gas chromatography. Potential differences in terpene composition were explored using principal component analysis using the package FactoMineR (Lê et al., 2008), and were visualized using the package factoextra (Kassambara and Mundt, 2020) in R version 4.0.5. Parallel analysis using the package paran (Dinno, 2018) was used to determine the number of principal components to retain for interpretation.

Permutational multivariate ANOVA (PERMANOVA) was used to test for differences in measured terpene content between treatment groups, and permutational analyses of multivariate dispersions (PERMDISP) was used to test the homogeneity of dispersions

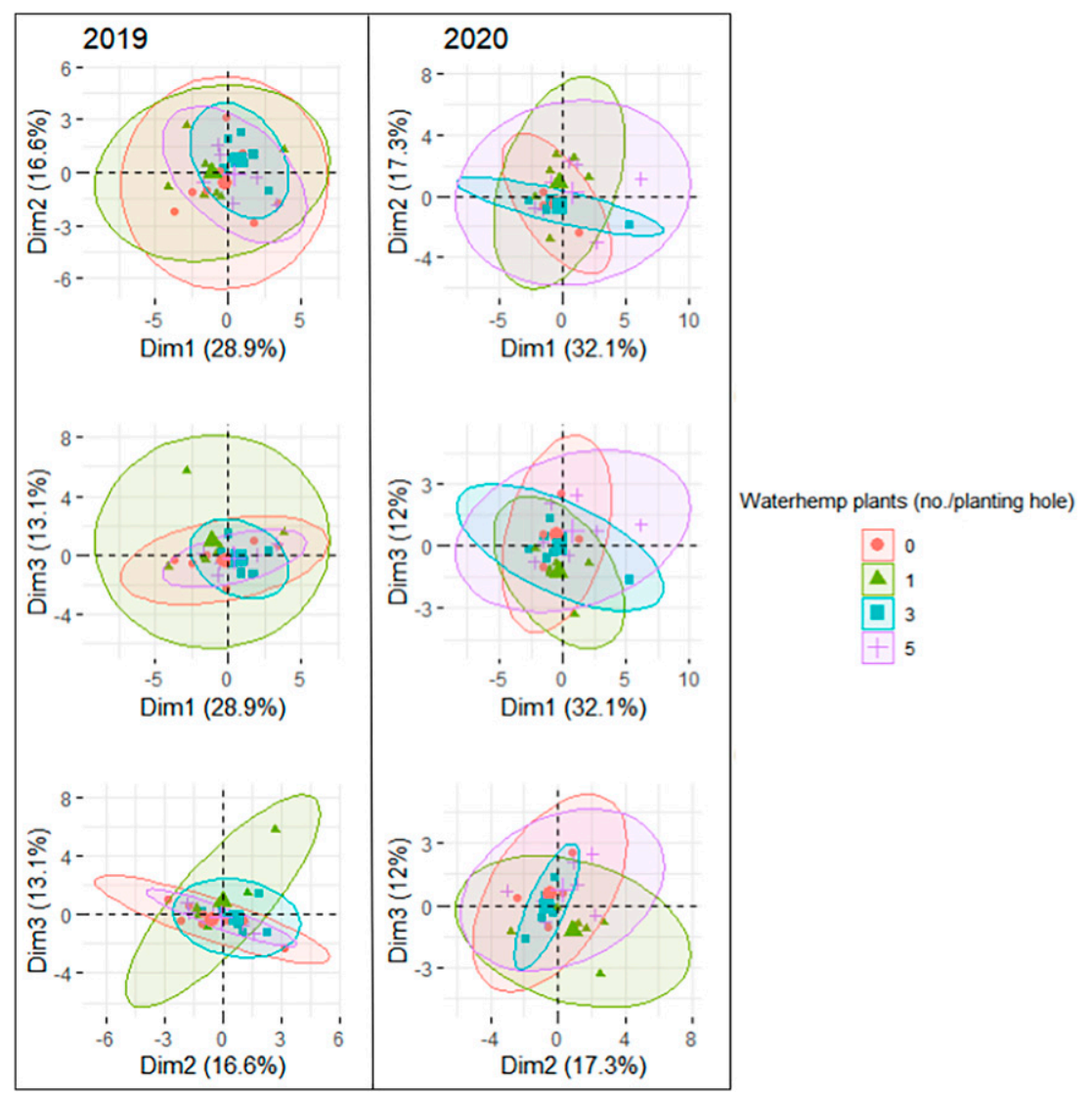

Fig. 2. Principal component analysis of measured hemp terpene content in (left) 2019 and (right) 2020 in response to competition with zero, one, three, or five waterhemp plants per planting hole. Three dimensions (Dim1, Dim2, and Dim3) are compared. Individual observations are represented by points, and treatments are bound by colored $95 \%$ confidence ellipses. Note the loadings for principal components are different between years (Figs. 4 and 5 ). 
for measured terpene concentrations. PERMANOVA and PERMDISP are nonparametric multivariate methods testing the equivalence of centroids and dispersions, respectively. PERMANOVA and PERMDISP were conducted on Euclidian distances in $\mathrm{R}$ using the package vegan (Oksanen et al., 2017).

GrowTH AND YIELD DATA. Linear mixed-effect models were used to test for the effects of planted waterhemp density on aboveground hemp biomass, stripped hemp floral biomass, and final aboveground height. Planted waterhemp density was modeled as a fixed effect, whereas block was modeled as a random effect. A repeated-measure, linear mixed-effect model was fitted to test for the effects of time, planted waterhemp density, and their interaction on hemp height. Time and waterhemp density were modeled as fixed effects whereas plant nested within block was modeled as a random effect.

WATERHEMP BIOMASS ACCUMULATION. Total waterhemp biomass in response to hemp and waterhemp density was analyzed as a two-factor aligned-rank transformed ANOVA in $\mathrm{R}$ with the package ARTool (Wobbrock et al., 2011). Two-factor aligned-rank transformed ANOVA is a flexible, nonparametric method that facilitates tests for interactions and was used because of heterogeneity in variances. Hemp and waterhemp density were modeled as fixed effects, and block was treated as a random effect. To accommodate a test for interaction, the "control" treatment lacking any waterhemp was dropped from the analysis.

\section{Results}

Phytochemistry. Hemp in our study occasionally accumulated substantial amounts of total THC. In 2019 , there was a single plant that accumulated $4.45 \%$ total THC, whereas all other measured plants accumulated between $0.22 \%$ and $0.53 \%$ total THC. In 2020, three plants accumulated $5.22 \%, 4.24 \%$, and $4.04 \%$ total THC. All other hemp plants in 2020 accumulated between $0.28 \%$ and $0.83 \%$ total THC.

In both 2019 and 2020, there were no significant effects of waterhemp competition treatment on total CBD (Table 2) or total THC (Fig. 1).
However, most plants had violative levels of total THC. There was no statistically significant effect of

competition on total terpene content in $2019\left[\mathrm{~F}_{(3,21)}=0.55, P=0.65(3\right.$ and 21 are the numerator and

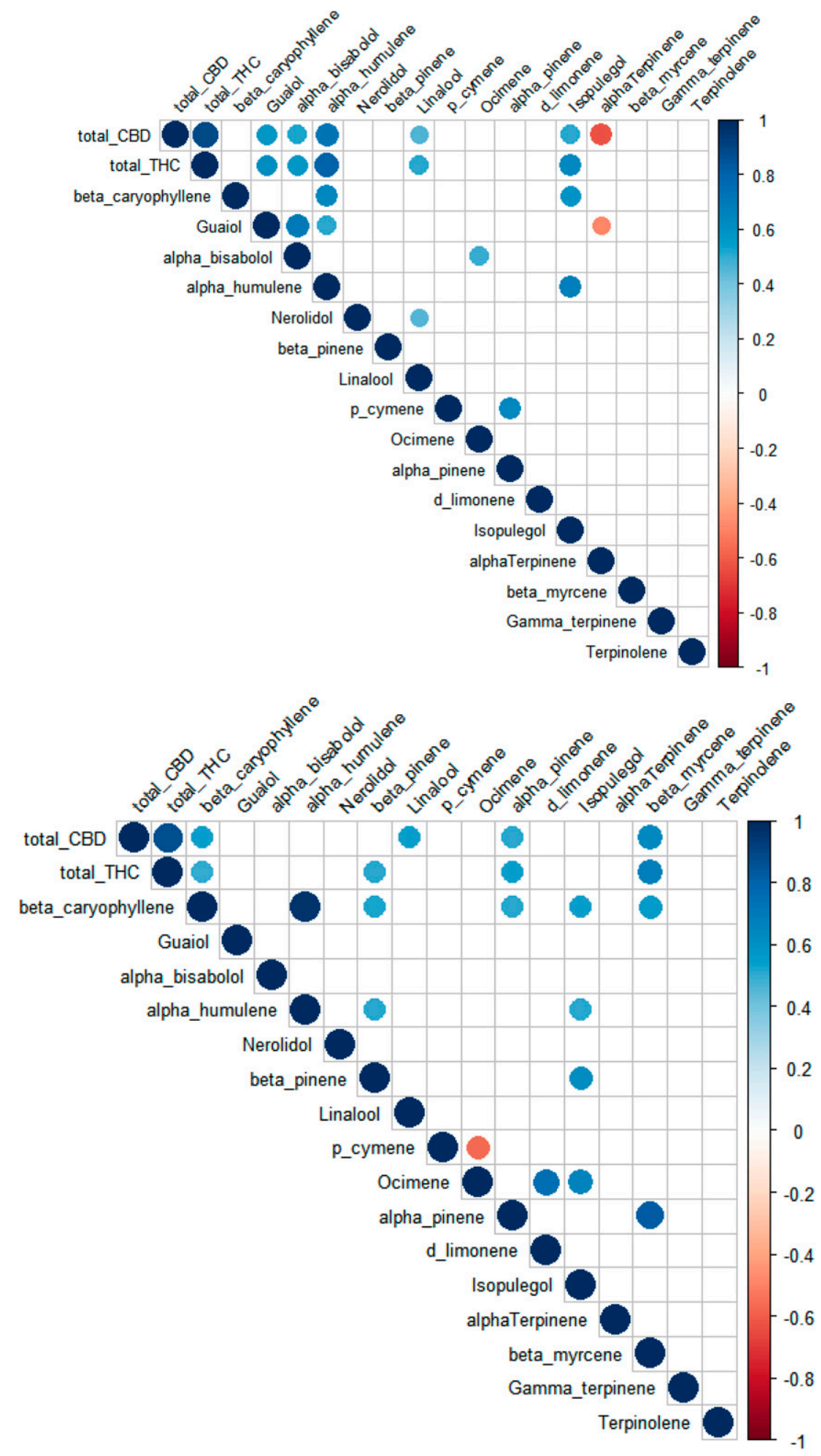

Fig. 3. Significant $(P<0.01)$ Pearson correlation coefficients for total cannabidiol (CBD), total tetrahydrocannabinol (THC), and terpene concentrations of hemp in (top) 2019 and (bottom) 2020. Correlations between measured metabolites were considered regardless of competition treatment (zero, one, three, or five waterhemp plants per planting hole). Positive coefficients are shown in blue and negative coefficients are shown in red. Nonsignificant correlations are not shown. Terpenes not detected in any sample were dropped from analysis. 
denominator df, respectively)] or $2020\left[\mathrm{~F}_{(3,17.89)}=0.74, P=0.54\right]$, and principal component analysis revealed no clear patterns between treatment and terpene composition (Fig. 2).

In 2019 , there was no significant effect of competition treatment on measured terpene composition [PERMANOVA, $\left.\mathrm{F}_{(3,27)}=0.42, P=0.87\right]$ or dispersion [PERMDISP, $\mathrm{F}_{(3,27)}=$ $1.23, P=0.35]$. In 2020, there was no significant effect of competition treatment on measured terpene composition [PERMANOVA, $\mathrm{F}_{(3,21)}=$ $0.63, P=0.52$ ] or dispersion [PERMDISP, $\left.\mathrm{F}_{(3,21)}=0.56, P=0.66\right]$.

Total measured terpene content was generally greater in 2020 (mean \pm SD, $\left.6138 \pm 2723 \mu \mathrm{g} \cdot \mathrm{g}^{-1}\right)$ than 2019 $\left(3869 \pm 762 \mu \mathrm{g} \cdot \mathrm{g}^{-1}\right)$. Although there were no significant differences in centroid location or dispersion resulting from competition treatment within year, there were significant correlations between measured secondary metabolites (Fig. 3). Furthermore, principal component loadings differed by year (Figs. 4 and 5), and hemp in 2020 contained more $\beta$-caryophyllene than in
2019 (Fig. 6). There was a strong correlation between total THC and total CBD across both years. In addition, there was a strong correlation between $\beta$-caryophyllene and $\alpha$-humulene across both years. Although there were multiple significant correlations between terpenes and total CBD or THC, the only terpene correlated consistently with total CBD across both years was linalool (Fig. 3).

Planted waterhemp density did not significantly affect total hemp biomass, stripped floral biomass, or final height of hemp plants in either year (Table 2). Furthermore, there was no significant effect of waterhemp competition on hemp height over time (Fig. 7).

In both 2019 and 2020, total waterhemp biomass was affected consistently by the presence of hemp (Fig. $8)$, but significant effects of waterhemp density, and hemp $\times$ waterhemp interactions were only observed in 2020 (Table 3).

\section{Discussion}

Despite its importance to producers, there is currently a lack of information regarding the effects of weed
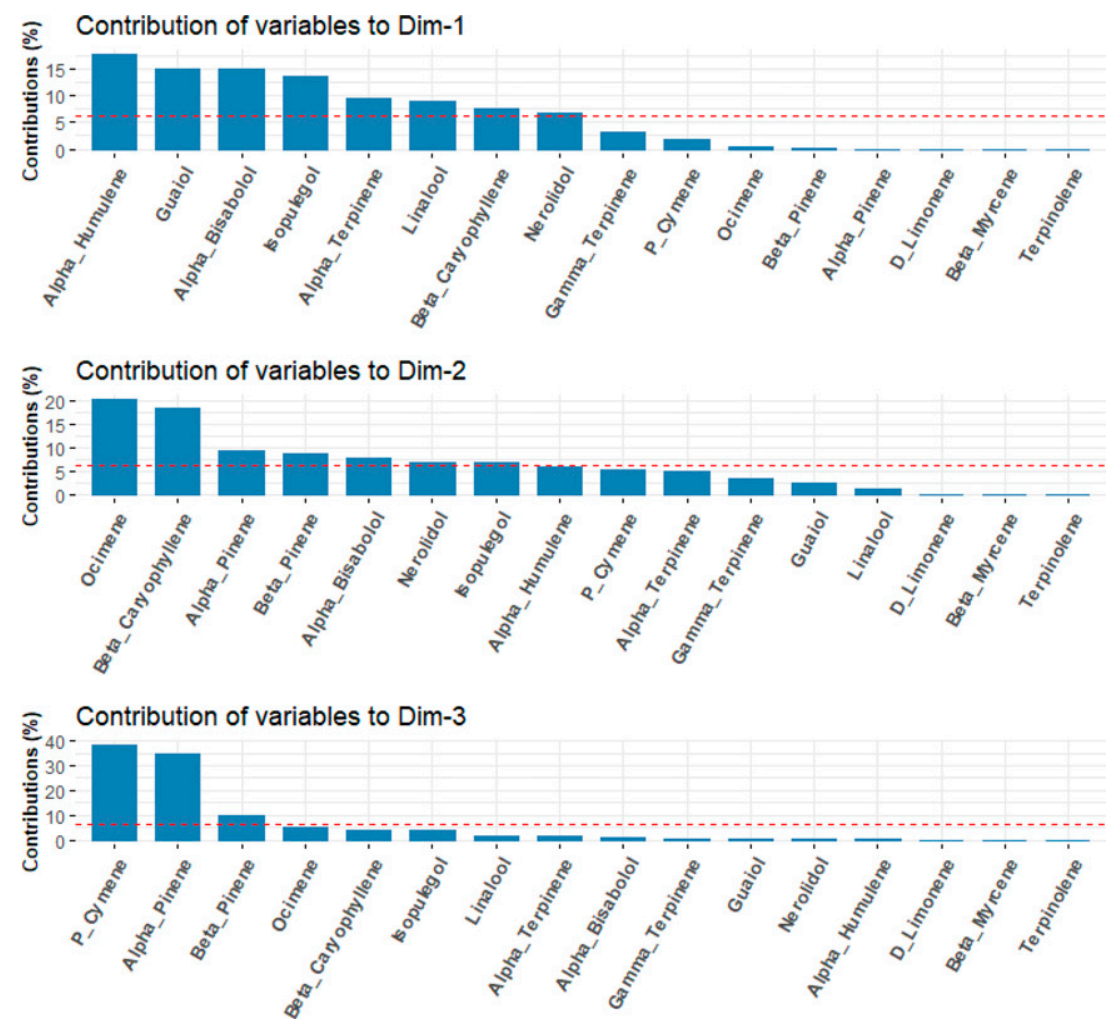

Fig. 4. Principal component loadings for measured terpene composition of hemp in response to competition with zero, one, three, or five waterhemp plants per planting hole in 2019 for three dimensions (Dim-1, Dim-2, Dim-3). The dashed horizontal line indicates the expected value if contributions were uniform. competition on hemp yield and chemical composition (Sandler and Gibson, 2019). In our study, we did not find evidence that competition from waterhemp is responsible for elevated levels of THC. This contrasts with the reported association between weed competition and elevated THC content in naturalized hemp populations (Haney and Kutscheid, 1973). Furthermore, we detected no significant differences in total CBD or terpene content and composition resulting from competition.

Our study underscores the challenges of outdoor CBD hemp production. The commercially available hemp used in our experiment routinely exceeded the $0.3 \%$ total THC threshold, rendering it noncompliant (Fig. 1). In addition to slight infractions, we also observed four plants with more than $1 \%$ total THC, the threshold for a negligent violation in the United States. Heterogeneity within an available hemp accession, and the capacity to accumulate violative levels of THC, have also been described in hemp variety trials (Stack et al., 2021), and represent a serious challenge to the developing hemp industry. A certificate of analysis provided by the supplier reported $12.8 \%$ total CBD and $0.25 \%$ total THC for the hemp accession 21 Mother PH4. Although performance of this accession in our study was comparable to specifications in the certificate of analysis, variability within and between years (Fig. 1) underscores the need for variety trials replicated across multiple environments. The chemical composition of hemp varies with age and developmental stage, with cannabinoid content generally being greatest during flowering (Aizpurua-Olaizola et al., 2016). During crop development, hemp plants can maintain total THC levels less than $0.3 \%$ until the very end of flowering. In this scenario, producers have sunk substantial costs into an unsaleable crop. Our study highlights the need for a greater understanding of the causes of cannabinoid accumulation.

We sampled and stored hemp in accordance with recommendations from the United Nations Office on Drugs and Crime (2009). However, sampling the uppermost $20 \mathrm{~cm}$ is also within the length range specified in the final rule set by the U.S. Department of Agriculture-Agriculture 

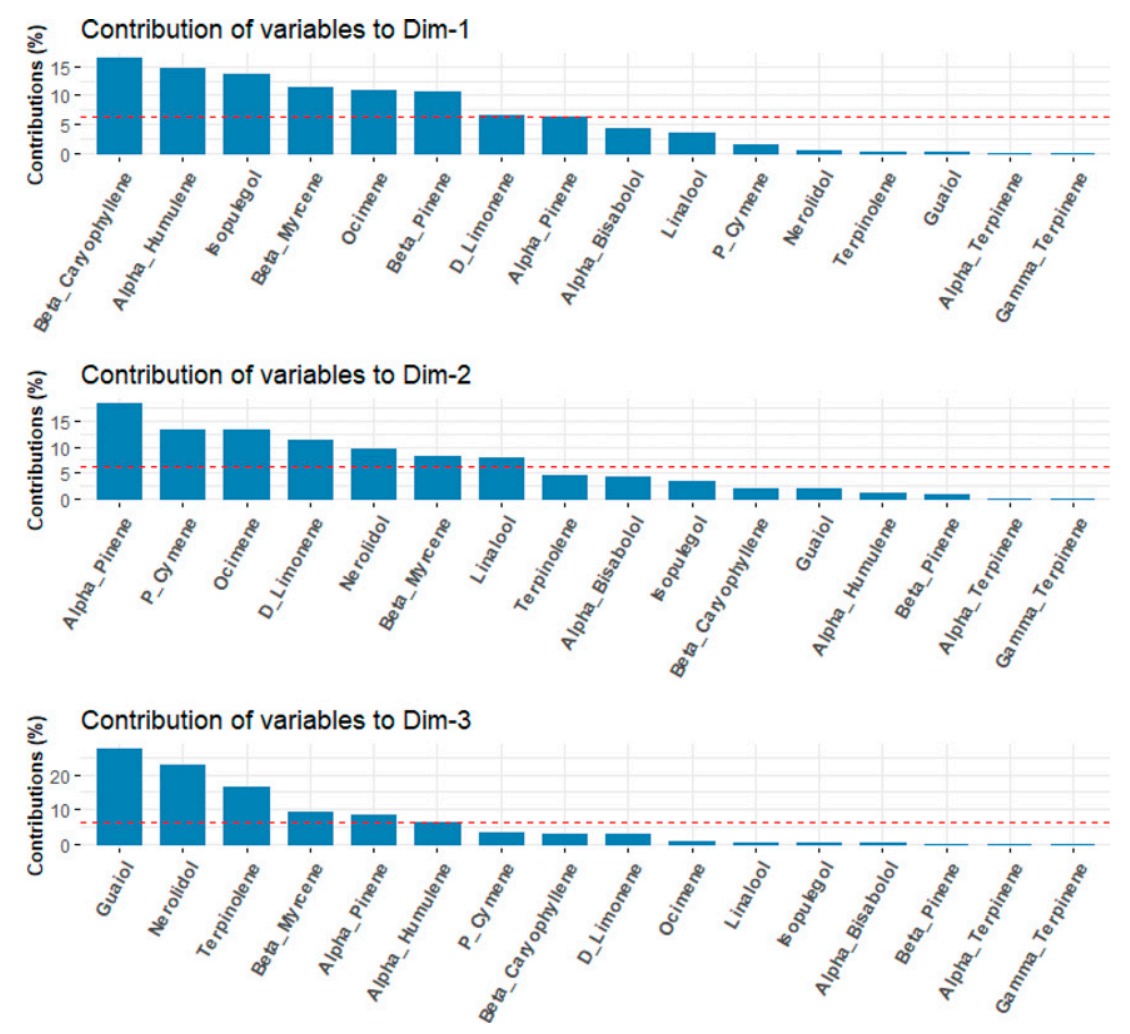

Fig. 5. Principal component loadings for measured terpene composition of hemp in response to competition with zero, one, three, or five waterhemp plants per planting hole in 2020 for three dimensions (Dim-1, Dim-2, Dim-3). The dashed horizontal line indicates the expected value if contributions were uniform.

Marketing Service (2021). We chose to sample hemp for chemical analysis at harvest to understand how seasonlong competition affects ultimate composition. However, the U.S. Department of Agriculture-Agriculture Marketing Service final rule allows compliance sampling up to $30 \mathrm{~d}$ before harvest, when hemp may have less total THC. Future work should investigate total THC content over time to understand more fully how weeds may affect compliance testing as well as the harvested crop. In addition to regulatory compliance sampling, future work should examine cannabinoid and terpene content throughout the whole plant instead of just the apical floral material to understand total chemical yield.

Total hemp biomass and stripped floral biomass was generally greater in 2019 than 2020, despite glyphosate injury, whereas total measured terpenes, $\mathrm{CBD}$, and $\mathrm{THC}$ were greater in 2020. Although differences in growing conditions likely contributed to these results (Fig. 9), the effects of glyphosate on hemp should be explored further. Although high doses of glyphosate are herbicidal, lower

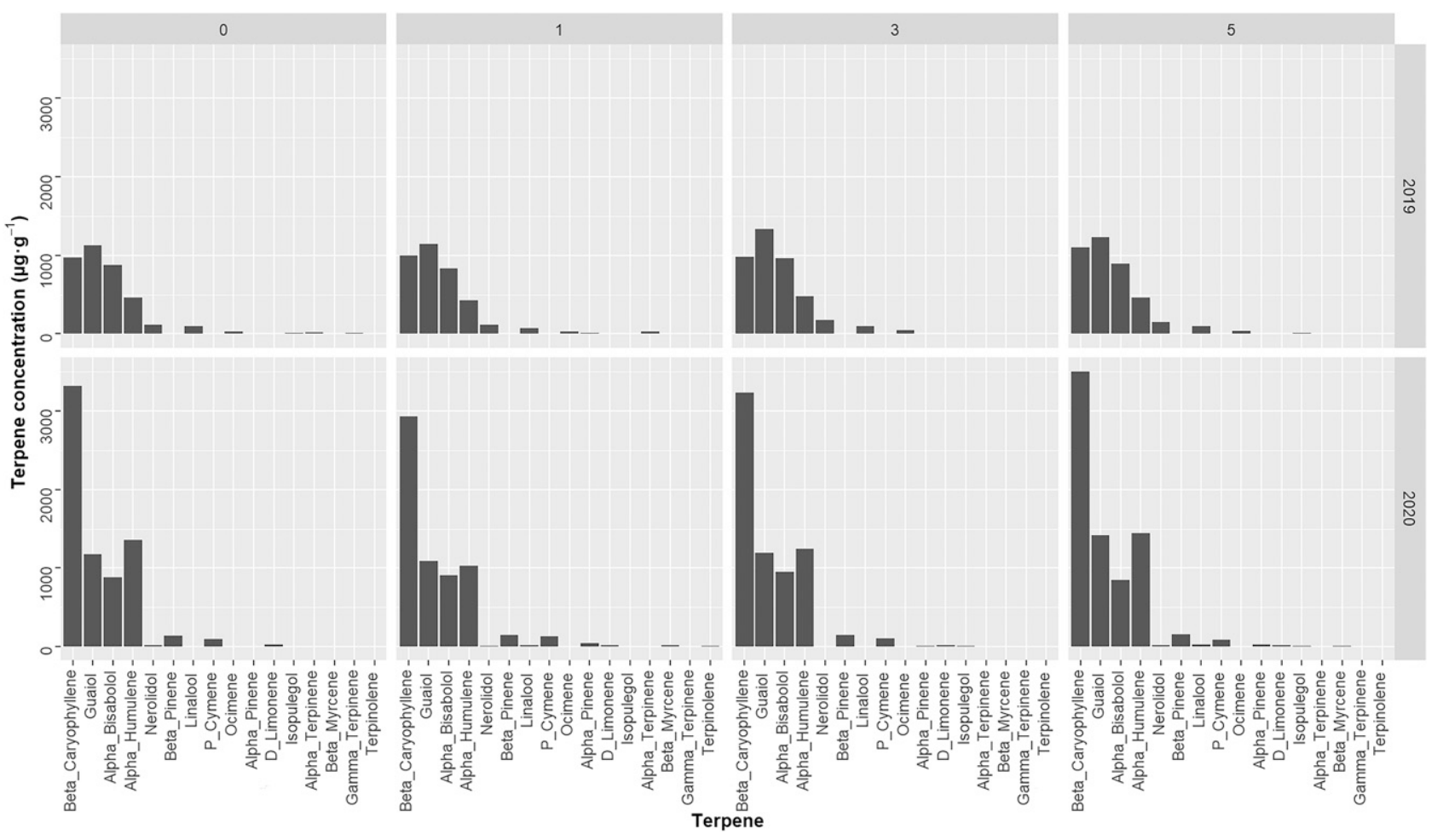

Fig. 6. Average concentration of measured hemp terpenes in 2019 and 2020 with zero, one, three or five waterhemp plants per planting hole. Terpenes not detected in any sample are not shown; $1 \mu \mathrm{g} \cdot \mathrm{g}^{-1}=1 \mathrm{ppm}$. 


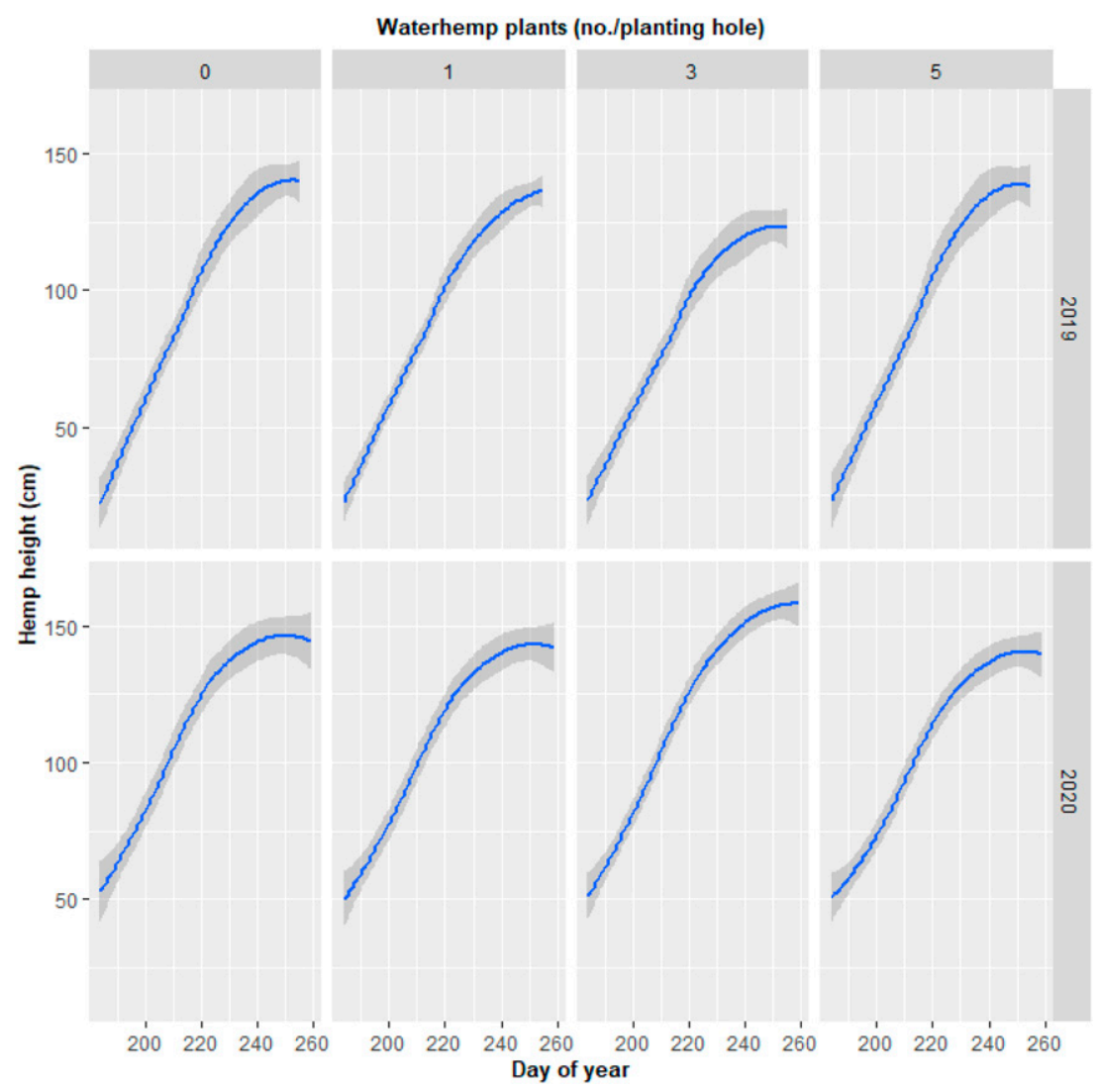

Fig. 7. Hemp height over time in 2019 and 2020 in response to competition from zero, one, three, or five waterhemp plants per planting hole. There was no significant effect of waterhemp competition treatment on hemp height over time; $1 \mathrm{~cm}=0.3937$ inch .
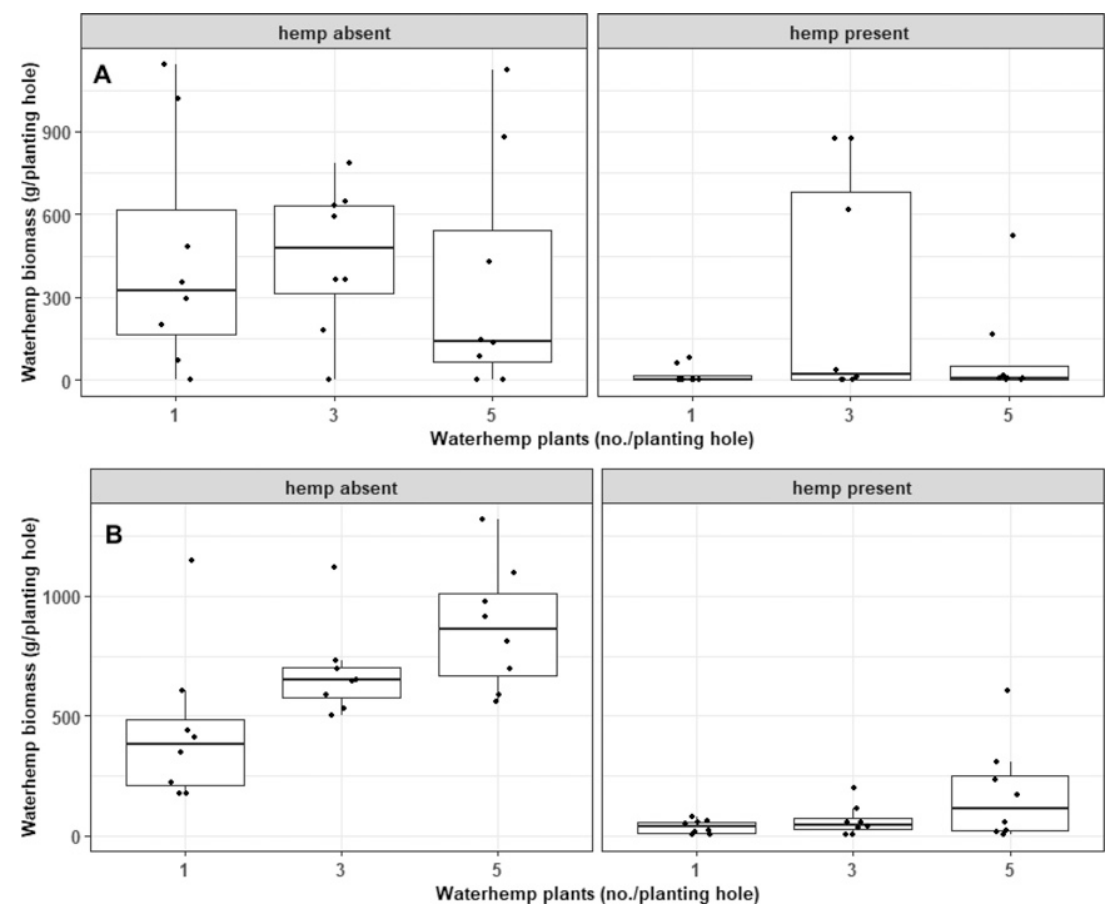

Fig. 8. Total waterhemp biomass in (A) 2019 and (B) 2020 in response to three densities (one, three, or five waterhemp plants), with or without competition from hemp; $1 \mathrm{~g}=0.0353 \mathrm{oz}$. doses could have more subtle effects on growth and chemical composition. Low doses of glyphosate can stimulate growth and could be involved in differences between hemp biomass in 2019 and 2020 (Brito et al., 2017). Glyphosate acts on 5-enolpyruvylshikimate-3-phosphate synthase and is not known to affect cannabinoid or terpene synthesis directly. However, plant responses to glyphosate are complex and could affect cannabinoid or terpene synthesis in hemp indirectly. Accordingly, glyphosate decreases terpene content in tomato (Solanum lycopersicum) leaves via an unknown mechanism (Ganugi et al., 2021). Future work should investigate specifically the effects of glyphosate on hemp secondary metabolism and growth.

In accordance with previous observations (Sandler and Gibson, 2019; Wilsie et al., 1944), hemp plants in our study were highly competitive and suppressed the growth of an aggressive weed for which management options are limited (Tranel et al., 2011). Size disparity between hemp transplants and waterhemp seedlings may explain the competitive ability of hemp grown from transplants. Also, the ample water and nitrogen provided through drip irrigation may have made growth light limited, resulting in asymmetric competition (Schwinning and Weiner, 1998). In our study, waterhemp growth was strongly suppressed by the presence of hemp (Fig. 5), but no significant yield loss of hemp was detected. Our findings are in accordance with observations by researchers working in fiber and grain hemp who generally report that vigorous stands of hemp suppress weeds effectively. Reduction in waterhemp biomass is encouraging, as biomass and seed number correlate strongly in waterhemp (Schwartz et al., 2016). Further work should focus on the effects of hemp grown in lower intensity crop rotations, interrogating the potential of hemp to reduce the reproduction of troublesome weeds (Westerman et al., 2005).

The highly variable phenotypes and uncontrollable sources of variation observed in our study likely limited our ability to detect a significant effect of weed competition on total or stripped floral biomass yield. For example, in 2020 , hemp grown in weed-free conditions ranged from 317 to $1152 \mathrm{~g} /$ plant, with an SD of $288 \mathrm{~g}$. Our study 
Table 3. Results of a two-way aligned rank transformation analysis of variation on waterhemp biomass in response to waterhemp and hemp densities. Significant $(P<0.05)$ effects are in bold type.

\begin{tabular}{lrrccr}
\hline & Yr & F value & Numerator df & Denominator df & $P$ value \\
\hline Hemp & 2019 & 9.92 & 1 & 35 & $<0.01$ \\
Waterhemp & & 0.59 & 2 & 35 & 0.55 \\
Hemp $\times$ waterhemp & & 0.93 & 2 & 35 & 0.40 \\
Hemp & 2020 & 102.89 & 1 & 35 & $<\mathbf{0 . 0 1}$ \\
Waterhemp & & 13.86 & 2 & 35 & $<\mathbf{0 . 0 1}$ \\
Hemp $\times$ waterhemp & 5.12 & 2 & 35 & $<\mathbf{0 . 0 1}$ \\
\hline
\end{tabular}

used hemp transplants grown from seed, and genetic variability within the accession could have potentially obscured treatment effects. Although the overall $\mathrm{F}$ test was nonsignificant, examining 95\% confidence intervals for treatment means shows there are potentially large differences in total hemp biomass and floral biomass when grown with or without waterhemp (Table 2).

We chose to study waterhemp because of its local abundance, economic impact, and competitive ability. However, there were no significant decreases in hemp biomass when grown in competition with up to five waterhemp plants. Competition with other weeds at greater densities could cause unambiguous, severe yield losses in hemp grown in plasticulture systems. For example, perennial weeds sprouting from vegetative structures may suffer less from initial size disparity than waterhemp. Future work should focus on weeds that can reproduce vegetatively such as honeyvine milkweed (Cynanchum laeve), johnsongrass (Sorghum halepense), and yellow nutsedge (Cyperus esculentus). In addition, direct-seeded hemp is likely more vulnerable to weed competition than transplants and should be the focus of future research.
Our study investigated the effect of weeds growing in planting holes. To that end, we controlled weeds in the row middles. However, weeds growing in row middles are also known to cause yield loss (Bonanno, 1996). Future work should investigate the utility and profitability of cultural and mechanical weed control for row middles. The lack of allowable herbicides and insecticides may make cover crops for weed suppression and beneficial-insect habitat an especially promising practice for hemp management as well as ecological intensification.

In conclusion, our study demonstrates that hemp can suppress the growth of a troublesome weed effectively for which methods of control are limited. Although we were not able definitively to determine whether weed competition has the potential to affect total THC and total CBD content in hemp, we - encouragingly - found no statistically significant hemp loss of total biomass or stripped hemp yield when grown in the presence of up to five waterhemp plants in plasticulture. To better address the relationship between hemp secondary metabolites and weed competitors, future studies

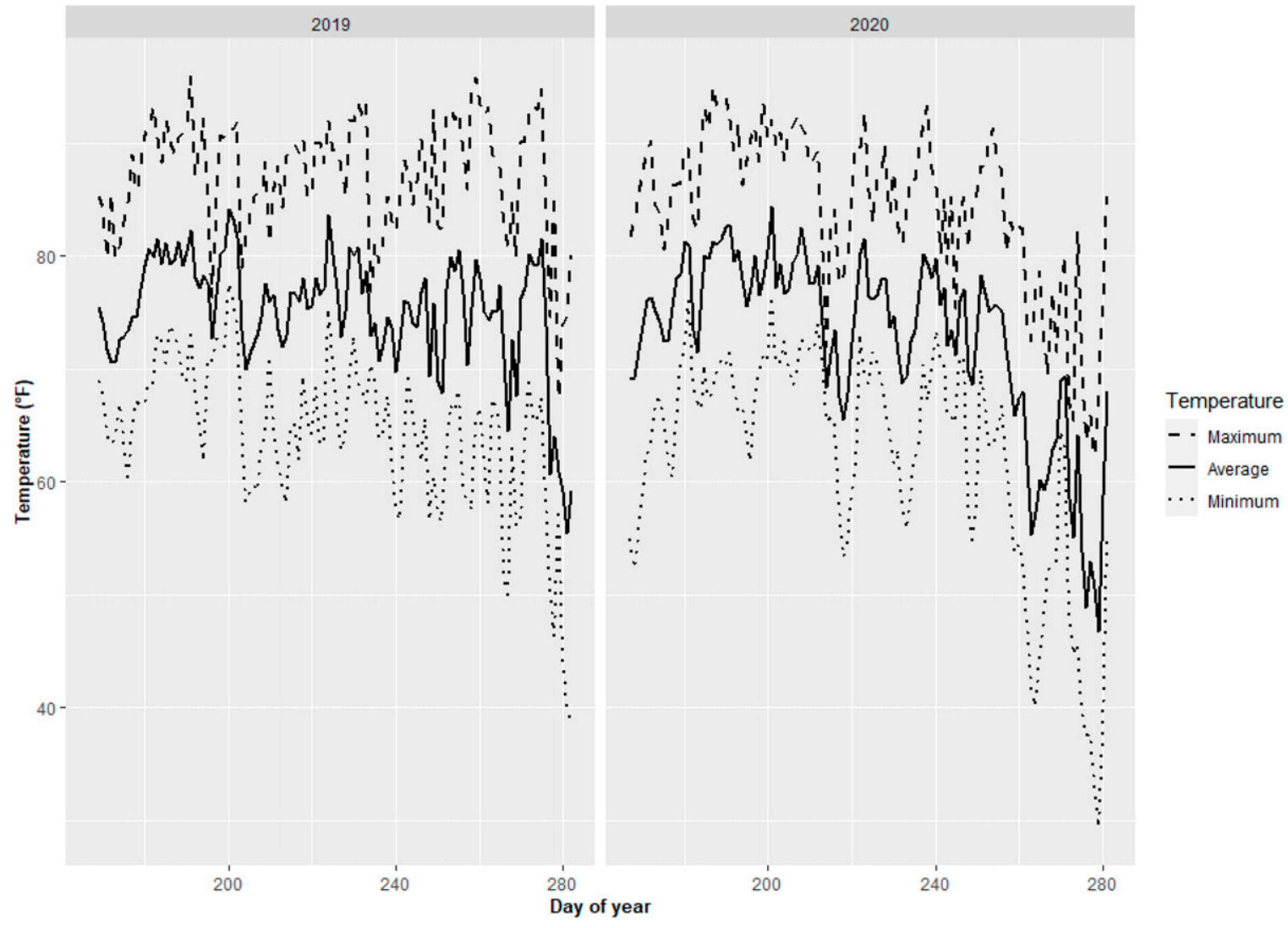

Fig. 9. Maximum, average, and minimum daily air temperatures for Carbondale, IL, in (left) 2019 and (right) 2020 during the periods between transplant and harvest; $\left({ }^{\circ} \mathrm{F}-32\right) \div 1.8={ }^{\circ} \mathrm{C}$. 
should investigate more intense competition in less luxuriant conditions than our study provided.

\section{Literature cited}

Aizpurua-Olaizola, O., U. Soydaner, E. Öztürk, D. Schibano, Y. Simsir, P. Navarro, N. Etxebarria, and A. Usobiaga. 2016. Evolution of the cannabinoid and terpene content during the growth of Cannabis sativa plants from different chemotypes. J. Nat. Prod. 79(2):324-331, https://doi.org/ 10.1021/acs.jnatprod.5b00949.

Alberti, P. 2021. Midwestern hemp database. 31 Aug. 2021. <https://extension. illinois.edu/global/midwestern-hempdatabase $>$.

Bates, D., M. Maechler, B. Bolker, and S. Walker. 2015. Fitting linear mixed-effects models using lme4. J. Stat. Softw. 67(1): 1-48, https://doi.org/10.18637/jss.v067. i01.

Bertucci, M.B., K.M. Jennings, D.W. Monks, J.R. Schultheis, F.J. Louws, and D.L. Jordan. 2019. Interference of palmer amaranth (Amaranthus palmeri) density in grafted and nongrafted watermelon. Weed Sci. 67(2):229-238, https://doi. org/10.1017/wsc.2018.77.

Bonanno, A.R. 1996. Weed management in plasticulture. HortTechnology 6:186189, https://doi.org/10.21273/horttech. 6.3.186.

Brito, I.P., L. Tropaldi, C.A. Carbonari, and E.D. Velini. 2017. Hormetic effects of glyphosate on plants. Pest Mgt. Sci. 74(5): 1064-1070, https://doi.org/10.1002/ ps.4523.

Butts, T.R., B.C. Vieira, D.O. Latorre, R. Werle, and G.R. Kruger. 2018. Competitiveness of herbicide-resistant waterhemp (Amaranthus tuberculatus) with soybean. Weed Sci. 66(6):729-737, https://doi. org/10.1017/wsc.2018.45.

Caplan, D., M. Dixon, and Y. Zheng. 2017. Optimal rate of organic fertilizer during the flowering stage for cannabis grown in two coir-based substrates. HortScience 52:1796-1803, https://doi. org/10.21273/HORTSCI12401-17.

Caplan, D., M. Dixon, and Y. Zheng. 2019. Increasing inflorescence dry weight and cannabinoid content in medical cannabis using controlled drought stress. HortScience 54:964-969, https://doi. org/10.21273/HORTSCI13510-18.

Devinsky, O., M.R. Cilio, H. Cross, J. Fernandez-Ruiz, J. French, C. Hill, R. Katz, V. Di Marzo, D. Jutras-Aswad, W.G. Notcutt, J. Martinez-Orgado, P.J. Robson, B.G. Rohrback, E. Thiele, B. Whalley, and D. Friedman. 2014. Cannabidiol:
Pharmacology and potential therapeutic role in epilepsy and other neuropsychiatric disorders. Epilepsia 55(6):791-802, https://doi.org/10.1111/epi.12631.

Dinno, A. 2018. Paran: Horn's test of principal components/factors: $\mathrm{R}$ package version 1.5.2. 31 Aug. 2021. <https:// CRAN.R-project.org/package $=$ paran $>$.

Ellison, S. 2021. Hemp (Cannabis sativa L.) research priorities: Opinions from United States hemp stakeholders. Glob. Change Biol. Bioenergy 13(4):562-569, https://doi.org/10.1111/gcbb.12794.

Fike, J.H., H. Darby, B.L. Johnson, L. Smart, and D.W. Williams. 2020. Industrial hemp in the USA: A brief synopsis, p. 89-109. In: M. Altieri and C. Nicholls (eds.). Sustainable agriculture reviews 42: Hemp production and applications. Springer, Cham, Switzerland.

Flessner, M.L., K.W. Bamber, and J.H. Fike. 2020. Evaluating herbicide tolerance of industrial hemp (Cannabis sativa L.). Crop Sci. 60(1):419-427, https://doi. org/10.1002/csc2.20055.

Flores-Sanchez, I.J. and R. Verpoorte. 2008. Secondary metabolism in cannabis. Phytochem. Rev. 7(3):615-639, https:// doi.org/10.1007/s11101-008-9094-4.

Ganugi, P., B. Miras-Moreno, P. GarciaPerez, L. Lucini, and M. Trevisan. 2021. Concealed metabolic reprogramming induced by different herbicides in tomato. Plant Sci. 303:110727, https://doi.org/ 10.1016/j.plantsci.2020.110727.

Gertsch, J., M. Leonti, S. Raduner, I. Racz, J.Z. Chen, X.Q. Xie, K.H. Altmann, M. Karsak, and A. Zimmer. 2008. Beta-caryophyllene is a dietary cannabinoid. Proc. Natl. Acad. Sci. USA 105(26):90999104, https://doi.org/10.1073/pnas.08 03601105 .

Gilbert, A.N. and J.A. DiVerdi. 2018. Consumer perceptions of strain differences in cannabis aroma. PLoS One 13(2):e019 2247, https://doi.org/10.1371/journal. pone.0192247.

Guimarães, A.C., L.M. Meireles, M.F. Lemos, M.C. Guimarães, D.C. Endringer, M. Fronza, and R. Scherer. 2019. Antibacterial activity of terpenes and terpenoids present in essential oils. Molecules 24(13):2471, https://doi.org/10.3390/ molecules24132471.

Haney, A. and B.B. Kutscheid. 1973. Quantitative variation in the chemical constituents of marihuana from stands of naturalized Cannabis sativa L. in east-central Illinois. Econ. Bot. 27(2):193-203.

Heap, I. 2021. The international herbicideresistant weed database. 31 Aug. 2021.
<http://www.weedscience.org/Pages/ Species.aspx $>$.

Izaguirre, M.M., C.A. Mazza, M. Biondini, I.T. Baldwin, and C.L. Ballaré. 2006. Remote sensing of future competitors: Impacts on plants defenses. Proc. Natl. Acad. Sci. USA 103(18):7170-7174, https://doi.org/10.1073/pnas.050980 5103.

Kassambara, A. and F. Mundt. 2020. Factoextra: Extract and visualize the results of multivariate data analyses: $\mathrm{R}$ package version 1.0.7. 31 Aug. 2021. <https://CRAN. R-project.org/package=factoextra $>$.

Kato-Noguchi, H. 2011. Barnyard grassinduced rice allelopathy and momilactone B. J. Plant Physiol. 168(10):1016-1020, https://doi.org/10.1016/j.jplph.2010.12. 021.

Khameneh, B., M. Iranshahy, V. Soheili, and B.S.F. Bazzaz. 2019. Review on plant antimicrobials: A mechanistic viewpoint. Antimicrob. Resist. Infect. Control 8(1): 1-28, https://doi.org/10.1186/s13756019-0559.

Lê, S., J. Josse, and F. Husson. 2008. FactoMineR: An $\mathrm{R}$ package for multivariate analysis. J. Stat. Softw. 25(1):1-18, https://doi.org/10.18637/jss.v025.i01.

McPartland, J.M. and Z. Sheikh. 2018. A review of Cannabis sativa-based insecticides, miticides, and repellents. J. Entomol. Zool. Stud. 6(6):1288-1299.

Oksanen, J., F.G. Blanchet, M. Friendly, R. Kindt, P. Legendre, D. McGlinn, P.R. Minchin, R.B. O'Hara, G.L. Simpson, P. Solymos, M.H.M. Stevens, E. Szoecs, and H. Wagner. 2017. Vegan: Community ecology package: $\mathrm{R}$ package version $2.5-2$. 31 Aug. 2021. <https://CRAN.R-project. org $/$ package $=$ vegan $>$.

Sandler, L.N. and K.A. Gibson. 2019. A call for weed research in industrial hemp (Cannabis sativa L). Weed Res. 59(4): 255-259, https://doi.org/10.1111/wre. 12368 .

Schwartz, L.M., J.K. Norsworthy, B.G. Young, K.W. Bradley, G.R. Kruger, V.M. Davis, L.E. Steckel, and M.J. Walsh. 2016. Tall waterhemp (Amaranthus tuberculatus) and palmer amaranth (Amaranthus palmeri) seed production and retention at soybean maturity. Weed Technol. 30(1):284-290, https://doi. org/10.1614/WT-D-1.

Schwinning, S. and J. Weiner. 1998. Mechanisms determining the degree of size asymmetry in competition among plants. Oecologia 113(4):447-455, https://doi. org/10.1007/s004420050397.

Sommano, S.R., C. Chittasupho, W. Ruksiriwanich, and P. Jantrawut. 2020. The 
cannabis terpenes. Molecules 25(24):5792, https://doi.org/10.3390/molecules 2524 5792 .

Stack, G.M., J.A. Toth, C.H. Carlson, A.R. Cala, M.I. Marrero-González, R.L. Wilk, D.R. Gentner, J.L. Crawford, G. Philippe, J.K.C. Rose, D.R. Viands, C.D. Smart, and L.B. Smart. 2021. Seasonlong characterization of high-cannabinoid hemp (Cannabis sativa L.) reveals variation in cannabinoid accumulation, flowering time, and disease resistance. Glob. Change Biol. Bioenergy 13(4):546-561, https://doi.org/10.1111/gcbb.12793.

Toth, J.A., G.M. Stack, A.R. Cala, C.H. Carlson, R.L. Wilk, J.L. Crawford, D.R. Viands, G. Philippe, C.D. Smart, J.K. Rose, and L.B. Smart. 2020. Development and validation of genetic markers for sex and cannabinoid chemotype in Cannabis sativa L. Glob. Change Biol. Bioenergy 12(3):213-222, https://doi. org/10.1111/gcbb.12667.

Tranel, P.J., C.W. Riggins, M.S. Bell, and A.G. Hager. 2011. Herbicide resistance in Amaranthus tuberculatus. A call for new options. J. Agr. Food Chem. 59(11): 5808-5812, https://doi.org/10.1021/ jfl03797n.
United Nations Office on Drugs and Crime. 2009. Recommended methods for the identification and analysis of cannabis and cannabis products, manual for use by national drug analysis laboratories. United Nations Office on Drugs and Crime, Vienna, Austria.

U.S. Department of Agriculture, Agriculture Marketing Service. 2021. Establishment of a domestic hemp production program. 31 Aug. 2021. <https://www. federalregister.gov/documents/2021/ 01/19/2021-00967/establishment-ofa-domestic-hemp-production-program $>$.

U.S. House of Representatives. 2018. H.R.2: Agriculture Improvement Act of 2018. 31 Aug. 2021. <https://www. congress.gov/bill/115th-congress/housebill $/ 2>$.

Van Wychen, L. 2019. Survey of the most common and troublesome weeds in broadleaf crops, fruits and vegetables in the United States and Canada. 31 Aug. 2021. <http://wssa.net/wp-content/uploads/ 2019-Weed-Survey_broadleaf-crops.xlsx $>$.

Westerman, P.R., M. Liebman, F.D. Menalled, A.H. Heggenstaller, R.G. Hartzler, and P.M. Dixon. 2005. Are many little hammers effective? Velvetleaf (Abutilon theophrasti) population dynamics in twoand four-year crop rotation systems. Weed Sci. 53(3):382-392, https://doi.org/ 10.1614/ws-04-130r.

Wilsie, C.P., C.A. Black, and A.R. Aandahl. 1944. Hemp production experiments: Cultural practices and soil requirements. Iowa Agr. Expt. Sta. Bul. P63, Iowa State College, Ames, IA.

Wobbrock, J.O., L. Findlater, D. Gergle, and J.J. Higgins. 2011. The aligned rank transform for nonparametric factorial analyses using only ANOVA procedures. Proc. SIGCHI Conf. Hum. Factor Comput. Syst. 143-146, https://doi.org/ $10.1145 / 1978942.1978963$.

Yang, L., K.S. Wen, X. Ruan, Y.X. Zhao, F. Wei, and Q. Wang. 2018. Response of plant secondary metabolites to environmental factors. Molecules 23(4):762, https://doi. org/10.3390/molecules23040762.

Zou, S. and U. Kumar. 2018. Cannabinoid receptors and the endocannabinoid system: Signaling and function in the central nervous system. Intl. J. Mol. Sci. 19(3):833, https://doi.org/10.3390/ijms 190 30833 . 

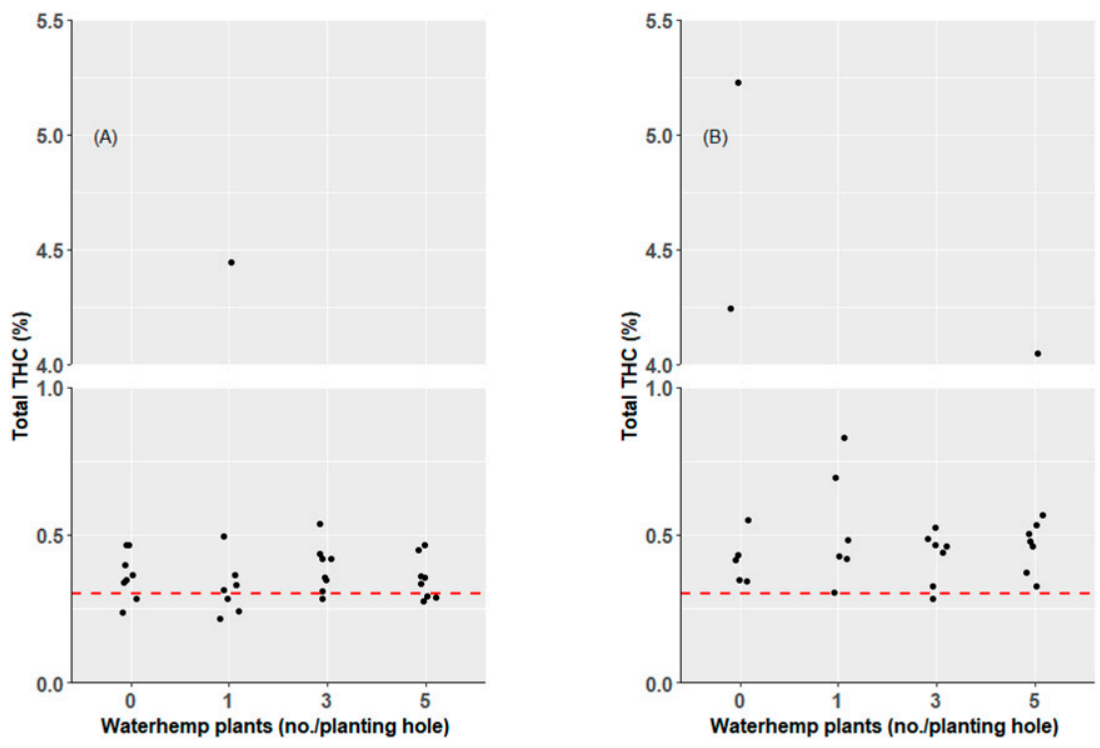

Supplemental Fig. 1. Total tetrahydrocannabinol (THC) of hemp in response to competition from zero, one, three, or five waterhemp plants in (A) 2019 or (B) 2020 . Total THC is determined by the formula: THC + $(0.877 \times$ THCa $)$, where THCa is tetrahydrocannabidiolic acid. Solid black dots represent individual observations. The dashed red line represents the $0.3 \%$ regulatory threshold. Note the break in $y$-axis. There was no significant effect of waterhemp competition on THC content with analysis by aligned-rank transformed analysis of variance in $2019\left[\mathrm{~F}_{(3,21)}=0.37, P=0.77\right]$ or in $2020\left[\mathrm{~F}_{(3,18.4)}=0.30\right.$, $P=0.83$ ] 